

\title{
Identifying childhood diarrhoea training needs of Nigerian frontline health care workers
}

\section{Sadoh $\mathrm{AE}^{* 1}$, Okoro $\mathrm{C}^{2}$, Mbarie $\mathrm{I}^{3}$}

1 Institute of Child Health, University of Benin, Benin City, Nigeria

${ }^{2}$ Alimaz Hospital, 13 Ewulere Street, Alimosho, Lagos, Nigeria

${ }^{3}$ Edo State Primary Health Care Development Agency, Benin City, Nigeria

\section{*Correspondence: Professor AE Sadoh, Institute of Child Health, University of Benin, Benin City, Edo State,} Nigeria; Email: evawere.sadoh@uniben.edu; ORCID - https://orcid.org/0000-0002-5681-9547

\begin{abstract}
Background: Health education and case management are important in the reduction of morbidity and mortality resulting from childhood diarrhoea.

Objective: To identify the training needs of health care workers as a measure of their empowerment to fulfil their roles in the control of childhood diarrhoea.

Methods: This cross-sectional, descriptive study utilized a self-administered pre-tested questionnaire to obtain demographic information, knowledge about diarrhoea, features of dehydration, management, and prevention of diarrhoea from 165 health care workers drawn from the 18 local government areas of Edo state.

Results: Only $24(14.5 \%)$ of health care workers could correctly define diarrhoea. Majority of respondents could identify features of dehydration: thirst $161(97 \%)$, loss of skin turgor $149(90.3 \%)$ and irritability $142(86.1 \%)$ but 93 $(56.4 \%)$ and $52(31.5 \%)$ did not know that unconsciousness and passage of small volume/no urine respectively were features of dehydration. Only $15(9.1 \%)$ could correctly constitute Salt Sugar Solution (SSS). Up to $42.2 \%$ of health workers use antibiotics regularly to manage childhood diarrhoea while another $48.8 \%$ considered the use of antibiotics during the diarrhoeal episode a preventive strategy.

Conclusion: Frontline health care workers need periodic training and retraining with consistent supportive supervision to ensure that children with diarrhoea are appropriately evaluated and managed.

Keywords: Childhood, Diarrhoea, Health care workers, Training needs
\end{abstract}

\section{Introduction}

Diarrhoea remains a leading cause of death amongst under-fives globally, despite the reduction in absolute numbers of under-fives dying from diarrhoea from 4.6million in 1980 to 445,600 deaths in 2016. [1,2] These figures are unacceptable because the deaths are preventable by interventions that are already available. [2] The deaths from diarrhoea are disproportionately from low and middle-income countries and few countries are responsible for a large proportion of the deaths. [2,3] Nigeria and India, due to their large populations and moderate to the high burden of diarrhoea, were 
responsible for $42 \%$ of 499,000 global under-five deaths due to diarrhoea in 2015.[3]

The integrated Global Action Plan for Pneumonia and Diarrhoea (GAPPD) highlights protection, prevention, and treatment framework for pneumonia and diarrhoea interventions. [4] Some of the aspects of the framework depend on health care workers' knowledge, attitude and practice such as case management in the health facility and community. Previous studies have highlighted the low knowledge of health care workers about diarrhoea. ${ }^{[5,6]}$ In Jigawa State of Nigeria, $48 \%$ of 335 health care workers would give an antibiotic in addition to oral rehydration solution (ORS) to manage diarrhoea while only 30\% could correctly prepare salt sugar solution (SSS). ${ }^{[5]}$ In another study from Benin City, health care workers were noted to have suboptimal knowledge about zinc supplementation in childhood diarrhoea. [6] In several studies on caregivers in Nigeria, suboptimal knowledge and practice regarding home management of diarrhoea have been reported and many of the respondents in such studies cite health care workers as the source of their information. $[7,8]$

While several efforts have been put in place to empower and train health care workers, it is important to institute regular monitoring of knowledge level, attitude and practice to determine areas that need strengthening. This is especially important as experienced health care workers may leave service while new health care workers are employed hence the need to make the evaluation and training continuous. Therefore, this study was carried out to assess the knowledge and practice of health care workers (concerning childhood diarrhoea) to identify areas that need strengthening.

\section{Methods}

The study was carried out in Edo state which is in the South-south geopolitical zone of Nigeria, between July $30^{\text {th }}$ and August $8^{\text {th }}, 2018$. The state has 18 local government areas and three senatorial districts namely: Edo North, Edo Central, and Edo South senatorial districts. Frontline Health care workers drawn from the Primary Health care facilities in all 18 local government areas were recruited for training by the State Government as part of efforts to build human capacity. The health care workers from each senatorial district were trained in their districts by experts in Obstetrics and Gynaecology, Paediatrics and data management. Ethical clearance for the use of the data was obtained from the University of Benin, College of Medical Sciences Ethics committee.

Prior to a lecture on Childhood diarrhoea given by one of the authors, data was obtained from the participants, using a self-administered questionnaire which was used as part of the pretest for the training. The questionnaires were distributed before the commencement of the lecture and were completed within 20 minutes. The self-administered questionnaire was pretested among a group of health workers who were not part of the training. Following pretesting, some of the questions were re-phrased to ensure better clarity. The questionnaire sought information on diarrhoea, features of dehydration, management of diarrhoea and prevention of diarrhoea. The questionnaire also sought demographic data such as age, gender, designation, number of years of practice and whether respondents had received training on diarrhoea management in the past.

The questionnaires were numbered and at the point of data entry names of respondents were not included. Confidentiality was maintained with regards to the collected data. The data were entered into a Statistical Package for Social Sciences (SPSS) version 20 spread sheet and the analysis was done using the same software and 
GraphPad Instat 3. Responses to different questions were presented as simple proportions. Association of variables with various responses was tested using the Chi-Square test or Fishers Exact test as appropriate. Continuous variables such as age were presented as means with standard deviation. The level of statistical significance was set at $\mathrm{p}<0.05$ at $95 \%$ confidence interval.

\section{Results}

There were 165 respondents, comprising 145 $(87.9 \%)$ females and $9(5.4 \%)$ males (Table I). Eleven $(6.7 \%)$ respondents did not indicate their gender. Of the 165 respondents, 49 (29.6\%) were from Edo Central Senatorial District while 58
(35.2\%) each were from Edo North and Edo South Senatorial Districts respectively. The mean age (SD) of the respondents was $43.83 \pm$ 8.48 years. The majority of the respondents 66 $(40 \%)$ had been practicing the various professions for between 11 and 20 years. The health care workers included nurses $(86 ; 52.1 \%)$ and Community Health Extension Workers (CHEW) $(49 ; 29.7 \%)$. Other cadres are as shown in Table I. Of the 165 respondents, 75 (45.5\%) and $70(42.4 \%)$ had previously received trainings on Integrated Management of Childhood Illnesses (IMCI) and diarrhoea management respectively. Fifty $(35.7 \%)$ respondents had not received any of these trainings, $37(26.4 \%)$ had received one of the two trainings while 53 $(37.9 \%)$ had received both trainings.

Table I: Socio-demographic characteristics of the study population

\begin{tabular}{lll}
\hline Variable & Frequency & Percentage \\
\hline Gender & 9 & \\
Male & 145 & 8.5 \\
Female & & 87.9 \\
Age Group & 4 & 2.4 \\
$20-29$ & 36 & 21.8 \\
$30-39$ & 47 & 28.5 \\
$40-49$ & 40 & 24.3 \\
$50-59$ & 38 & 23.0 \\
Not indicated & & \\
Cadre of Health Care Worker & 86 & 52.1 \\
Nurse & 49 & 29.7 \\
CHEW & 9 & 5.5 \\
CHO & 21 & 12.7 \\
Not indicated & & \\
Duration of Practice & 42 & 25.4 \\
$\leq 10$ years & 66 & 40.0 \\
11-20 years & 32 & 19.4 \\
$\geq 21$ years & 25 & 15.2 \\
Not indicated & & \\
\hline
\end{tabular}

CHEW- Community Health Extension Worker, CHO - Community Health Officer

Knowledge about diarrhoea and clinical features of dehydration

Almost all the respondents attend to children with diarrhoea; $32(19.4 \%)$ frequently and 125 $(75.8 \%)$ sometimes. Only $24(14.5 \%)$ of the respondents could define diarrhoea correctly as the passage of three or more loose stools in 24 hours. Table II shows the respondents' knowledge of symptoms of dehydration. Majority 161(97.6\%) of the respondents knew that thirst was a feature of dehydration. Only $101(61.2 \%)$ knew that crying without tears was a 
feature of dehydration. More than $30 \%$ of the respondents did not know that passing small volume urine or no urine was a feature of dehydration. Only $62(37.6 \%)$ of the respondents knew all the four features (thirst, loss of skin turgor, irritability, and unconsciousness) used for the classification of dehydration in the IMCI schema.

Table: II Knowledge of health workers about clinical features of dehydration

\begin{tabular}{lllll}
\hline \multirow{2}{*}{ Feature of dehydration } & \multicolumn{3}{c}{ Correct Knowledge } \\
\cline { 2 - 4 } Thirst & $\mathrm{n}$ & Yes & $\mathrm{n}$ & No \\
Crying with tears & 161 & 97.6 & 4 & 2.4 \\
Crying without tears & 85 & 51.5 & 80 & 48.5 \\
Passing Urine normally & 101 & 61.2 & 64 & 38.8 \\
Passing small volume or no urine & 88 & 53.3 & 77 & 46.7 \\
Loss of skin turgor & 113 & 68.5 & 52 & 31.5 \\
Irritability & 149 & 90.3 & 16 & 9.7 \\
Unconscious & 142 & 86.1 & 23 & 13.9 \\
*Composite signs & 72 & 43.6 & 93 & 56.4 \\
\hline${ }^{*}$ Comprises thirst loss of skin turgor, irritability, and unconsciousness & 37.6 & 103 & 62.4 \\
\hline
\end{tabular}

*Comprises thirst, loss of skin turgor, irritability, and unconsciousness

Treatment options and frequency of use of these options by the respondents are shown in Table III. Oral Rehydration Solution (ORS), Salt-SugarSolution and intravenous fluids (IVF) would be used in the management of diarrhoea by 151 (91.5\%), 154 (93.3\%) and 142 (86.1\%) of the respondents respectively. In terms of frequency, $147(89.1 \%)$ and 115 (69.7\%) would respectively use ORS and SSS always. IVF would be used by $93 \quad(56.4 \%) \quad$ only sometimes. Sulphamethoxazole/trimethoprim (SMX/TMP) combination and Metronidazole would always be used for managing diarrhoea by 32 (19.4\%) and $73(44.2 \%)$ of the respondents respectively. The majority of the respondents $(140 ; 84.9 \%)$ would always administer Zinc in the management of childhood diarrhoea. Other drugs that would be used in the management of diarrhoea and the proportion of respondents who would use them are as shown in Table III.

Only $18(10.9 \%)$ respondents knew the right quantity of water for preparing SSS while 112 $(67.8 \%)$ and 132 (80\%) knew the correct quantity of sugar and salt to be added to water respectively. Only $15(9.1 \%)$ respondents knew the correct quantity of water, salt, and sugar for preparing SSS.

Determinants of knowledge about diarrhoea, clinical features of dehydration and use of treatment options More CHEWs 11 (22.5\%) compared to CHOs 1 $(11.1 \%)$ and Nurses $7(8.1 \%)$ were able to define diarrhea correctly. The difference was significant $(p=0.03)$. Nurses $(70 ; 81.4 \%)$ were more likely to know that passing small or no urine was a sign of dehydration compared to CHEWs $(23 ; 46.9 \%$ and CHOs $(4 ; 44.4 \%)$ ( $\mathrm{p}<$ 0.0001 ) as shown in Table IV. The nurses were also more likely than CHEWs and $\mathrm{CHO}$ to know that irritability was a sign of dehydration $(p=0.01)$. Prior training was not significantly associated with knowledge of the clinical features of dehydration. Table $\mathrm{V}$ shows the association between the cadre of respondents and the use of treatment options for diarrhoea. Any use of intravenous fluids (always or sometimes) was more frequent by nurses $(29.1 \%$ and $61.6 \%$ ) and CHEWs (32.2\% and 53.1\%) compared to $\mathrm{CHOs}(22.2 \%$ and $33.3 \%)$. This association was significant $(\mathrm{p}<0.01)$. CHOs were more likely to use "Diapec" compared to 
nurses and CHEWs $(p=0.003)$. There was no significant association between cadre and the use of other treatment modalities. All treatment modalities were not significantly associated with previous training except for SMX/TMP, which was used more frequently by those who were previously trained compared to those who were $\operatorname{not}(\mathrm{p}=0.02)$.

Table III: Treatment modalities utilized by health care workers for treating childhood diarrhoea

\begin{tabular}{|c|c|c|c|c|c|c|c|c|}
\hline \multirow[t]{3}{*}{ Treatment modality } & \multicolumn{8}{|c|}{ Frequency of Use } \\
\hline & \multicolumn{2}{|c|}{ Always } & \multicolumn{2}{|c|}{ Sometimes } & \multicolumn{2}{|c|}{ Never } & \multicolumn{2}{|c|}{ No response } \\
\hline & $\mathrm{n}$ & $\%$ & $\mathrm{n}$ & $\%$ & $\mathrm{n}$ & $\%$ & $\mathrm{n}$ & $\%$ \\
\hline ORS & 147 & 89.1 & 4 & 2.4 & 0 & 0.0 & 14 & 8.5 \\
\hline SSS & 115 & 69.7 & 39 & 23.6 & 2 & 1.2 & 9 & 5.5 \\
\hline Intravenous fluid & 49 & 29.7 & 93 & 56.4 & 4 & 2.4 & 19 & 11.5 \\
\hline Cotrimoxazole & 32 & 19.4 & 50 & 30.3 & 52 & 31.5 & 31 & 18.8 \\
\hline Metronidazole & 73 & 44.3 & 49 & 29.7 & 22 & 13.3 & 21 & 12.7 \\
\hline “Lomotil" & 20 & 12.1 & 44 & 26.7 & 67 & 40.6 & 34 & 20.6 \\
\hline "Diastop" & 21 & 12.7 & 39 & 23.7 & 69 & 41.8 & 36 & 21.8 \\
\hline "Thalazole" & 5 & 3.1 & 37 & 22.4 & 72 & 43.6 & 51 & 30.9 \\
\hline "Diapec" & 8 & 4.8 & 17 & 10.3 & 80 & 48.5 & 60 & 36.4 \\
\hline Zinc & 140 & 84.9 & 9 & 5.5 & 3 & 1.9 & 13 & 7.9 \\
\hline Vitamin A & 60 & 36.3 & 32 & 19.4 & 45 & 27.3 & 28 & 17 \\
\hline
\end{tabular}

Knowing the composite features of dehydration and correct preparation of SSS were not significantly associated with the cadre of the respondents nor with previous training. (Figures 1 and 2)

\section{Knowledge of prevention of diarrhoea}

Table VI shows the knowledge of respondents about the prevention of diarrhoea. The majority of the respondents knew that breastfeeding, hand washing, and proper waste disposal are control strategies in diarrhoea. Only 100 (60.6\%) respondents knew that the boiling of drinking water was a control strategy for diarrhoea. Nearly half $(80 ; 48.5 \%)$ of the respondents, felt that antibiotics were preventive in diarrhoea.

\section{Discussion}

This study shows that diarrhoea is a fairly common disease affecting children as almost all the respondents attended to children with diarrhoea either frequently or sometimes. This is in keeping with global statistics which indicate that diarrhoea is a common cause of childhood morbidity and mortality amongst under-fives. [2,3] However, for such a common disease, it is surprising that less than $15 \%$ of health care workers could define diarrhoea. This is much less than $50.8 \%$ reported by Abdu et al. [5]

Dehydration is one of the major complications of diarrhoea that leads to mortality. Health workers must be able to recognize the features of dehydration. Being able to identify thirst, loss of skin turgor and alteration in mental status as key features of dehydration is necessary to classify the severity of dehydration and institute appropriate management according to the Integrated Management of Childhood Illnesses (IMCI). [9] More than $90 \%$ of the respondents knew that thirst and loss of skin turgor were features of dehydration while $86 \%$ knew that irritability was a feature of dehydration. 
Table IV: Association between knowledge of clinical features of diarrhoea, the cadre of health care worker and training on diarrhoea

\begin{tabular}{|c|c|c|c|c|c|c|c|}
\hline \multirow{3}{*}{$\begin{array}{l}\text { Knowledge of clinical } \\
\text { features }\end{array}$} & \multicolumn{3}{|c|}{ Cadre of health care worker } & \multicolumn{4}{|c|}{ Trained } \\
\hline & CHEW & $\mathrm{CHO}$ & Nurses & $P$ & Yes & No & $P$ \\
\hline & n (\%) & $\mathrm{n}(\%)$ & $\mathrm{n}(\%)$ & & $\mathrm{n}(\%)$ & $\mathrm{n}(\%)$ & \\
\hline \multicolumn{8}{|l|}{ Thirst } \\
\hline Correct & $47\{95.9)$ & $9(100.0)$ & $85(98.8)$ & & $88(97.8)$ & $49(98.0)$ & \\
\hline Wrong & $2(4.1)$ & $0(0.0)$ & $1(1.2)$ & 0.47 & $2(2.2)$ & $1(2.0)$ & 0.93 \\
\hline \multicolumn{8}{|l|}{ Crying with tears } \\
\hline Correct & $26(53.1)$ & $5(55.6)$ & $43(50.0)$ & & $52(57.8)$ & $32(64.0)$ & \\
\hline Wrong & $23(46.9)$ & $4(44.4)$ & $43(50.0)$ & 0.91 & $38(42.2)$ & $18(36.0)$ & 0.47 \\
\hline \multicolumn{8}{|l|}{ Crying without tears } \\
\hline Correct & $29(59.2)$ & $6(66.7)$ & $52(60.5)$ & & $52(57.8)$ & $34(68.0)$ & \\
\hline Wrong & $20(40.8)$ & $3(33.3)$ & $34(39.5)$ & 0.92 & $38(42.2)$ & $16(32.0)$ & 0.23 \\
\hline \multicolumn{8}{|l|}{ Passing urine normally } \\
\hline Correct & $22(44.9)$ & $5(55.6)$ & $53(61.6)$ & & $49(54.4)$ & $25(50.0)$ & \\
\hline Wrong & $27(55.1)$ & $4(44.4)$ & $33(38.4)$ & 0.17 & $41(45.6)$ & $25(50.0)$ & 0.61 \\
\hline \multicolumn{8}{|l|}{$\begin{array}{l}\text { Passing small volume } \\
\text { or no urine }\end{array}$} \\
\hline Correct & $23(46.9)$ & $4(44.4)$ & $70(81.4)$ & & $62(68.9)$ & $36(72.0)$ & \\
\hline Wrong & $26(53.1)$ & $5(55.6)$ & $16(18.6)$ & 0.0001 & $28(31.1)$ & $14(28.0)$ & 0.85 \\
\hline \multicolumn{8}{|l|}{ Loss of skin turgor } \\
\hline Correct & $41(83.7)$ & $7(77.8)$ & $82(95.3)$ & & $82(91.1)$ & $46(92.0)$ & \\
\hline Wrong & $8(16.3)$ & $2(22.2)$ & $4(4.7)$ & 0.04 & $8(8.9)$ & $4(8.0)$ & 0.86 \\
\hline \multicolumn{8}{|l|}{ Irritability } \\
\hline Correct & $37(75.5)$ & $6(66.7)$ & $80(93.0)$ & & $76(84.4)$ & $47(94.0)$ & \\
\hline Wrong & $12(24.5)$ & $3(33.3)$ & $6(7.0)$ & 0.01 & $14(15.6)$ & $3(6.0)$ & 0.11 \\
\hline \multicolumn{8}{|l|}{ Unconsciousness } \\
\hline Correct & $26(53.1)$ & $2(22.2)$ & $41(47.7)$ & & $41(45.6)$ & $19(38.0)$ & \\
\hline Wrong & $23(46.9)$ & $7(77.8)$ & $45(52.3)$ & 0.34 & $49(54.4)$ & $31(62.0)$ & 0.39 \\
\hline
\end{tabular}

CHEW- Community Health Extension Worker, CHO- Community Health Officer

However, more than $50 \%$ of the respondents did not know that unconsciousness was a feature of dehydration. In a clinical audit from Cross River State in Nigeria, it was noted that the level of consciousness was documented for only $21.9 \%$ of children with diarrhoea, highlighting inadequate evaluation of the children. [10] Acute kidney injury often results from diarrhoea and yet almost a third of the respondents did not know that passing small volume urine or not passing urine at all in a child with diarrhoea signifies dehydration. This is in keeping with the findings in the Cross River State audit where only $15.4 \%$ of diarrhoea cases had documentation on urine output. [10] This implies that inadequate evaluation may lead to inadequate patient management and possibly, death. With only $37 \%$ of the respondents knowing the four key features of dehydration, it means that such respondents may not be able to correctly classify the level of dehydration in children, thereby compromising treatment. Rehydration is life-saving in childhood diarrhoea. The development of ORS was heralded as one of the great medical achievements of the twentieth century and is the mainstay of the World Health Organization's efforts to reduce diarrhoea mortality. [11] 
Table Va: Association between treatments used for management of childhood diarrhoea, the cadre of health care worker and training on diarrhoea

\begin{tabular}{|c|c|c|c|c|c|c|c|}
\hline \multirow{3}{*}{$\begin{array}{l}\text { Treatment modality and } \\
\text { frequency of use }\end{array}$} & \multicolumn{3}{|c|}{ Cadre of Health care worker } & \multirow[t]{3}{*}{$P$} & \multicolumn{2}{|l|}{ Trained } & \multirow[t]{3}{*}{$P$} \\
\hline & CHEW & $\mathrm{CHO}$ & Nurse & & Yes & No & \\
\hline & $\mathrm{n}(\%)$ & $\mathrm{n}(\%)$ & $\mathrm{n}(\%)$ & & $\mathrm{n}(\%)$ & $\mathrm{n}(\%)$ & \\
\hline \multicolumn{8}{|l|}{ Oral rehydration Solution } \\
\hline Always & $48(98.0)$ & $6(66.7)$ & 77 (89.5) & \multirow{4}{*}{0.06} & $79(87.8)$ & $46(92.0)$ & \multirow{4}{*}{0.59} \\
\hline Sometimes & $0(0.0)$ & $1(11.1)$ & $2(2.3)$ & & $2(2.2)$ & $2(4.0)$ & \\
\hline Never & $0(0.0)$ & $0(0.0)$ & $0(0.0)$ & & $0(0.0)$ & $0(0.0)$ & \\
\hline Non-response & $1(2.0)$ & $2(22.2)$ & $7(8.2)$ & & $9(10.0)$ & $2(4.0)$ & \\
\hline \multicolumn{8}{|l|}{ Salt Sugar Solution } \\
\hline Always & 40 (81.6) & $5(55.6)$ & $55(64.0)$ & \multirow{4}{*}{0.31} & $66(73.3)$ & $31(62.0)$ & \multirow{4}{*}{0.22} \\
\hline Sometimes & $8(16.3)$ & $4(44.4)$ & $24(27.8)$ & & $18(20.0)$ & $16(32.0)$ & \\
\hline Never & $1(2.1)$ & $0(0.0)$ & $1(1.2)$ & & $1(1.1)$ & $0(0.0)$ & \\
\hline Non response & $0(0.0)$ & $0 .(0.0)$ & $6(7.0)$ & & $5(5.6)$ & $3(6.0)$ & \\
\hline \multicolumn{8}{|l|}{ Intravenous Fluids } \\
\hline Always & $16(32.2)$ & $2(22.2)$ & $25(29.1)$ & \multirow{4}{*}{$<0.01$} & $26(28.9)$ & $16(32.0)$ & \multirow{4}{*}{0.98} \\
\hline Sometimes & $26(53.1)$ & $3(33.3)$ & $53(61.6)$ & & $50(55.6)$ & $30(60.0)$ & \\
\hline Never & $1(2.0)$ & $2(22.2)$ & $0(0.0)$ & & $2(2.2)$ & $1(2.0)$ & \\
\hline Non-response & $6(12.2)$ & $2(22.2)$ & $8(9.3)$ & & $12(13.3)$ & $3(6.0)$ & \\
\hline \multicolumn{8}{|l|}{ SMX/TMP } \\
\hline Always & $10(20.4)$ & $2(22.2)$ & 15 (17.4) & \multirow{4}{*}{0.76} & $21(23.3)$ & $4(8.0)$ & \multirow{4}{*}{0.02} \\
\hline Sometimes & $18(36.7)$ & $2(22.2)$ & $23(26.7)$ & & $22(24.5)$ & $22(44.0)$ & \\
\hline Never & $14(28.6)$ & $4(44.4)$ & $30(34.9)$ & & $26(28.9)$ & $17(34.0)$ & \\
\hline Non response & $7(14.3)$ & $1(11.1)$ & $18(20.9)$ & & $21(23.3)$ & $7(14.0)$ & \\
\hline \multicolumn{8}{|l|}{ Metronidazole } \\
\hline Always & $19(38.8)$ & $3(33.3)$ & $40(46.5)$ & \multirow{4}{*}{0.0 .88} & $38(42.2)$ & $24(48.0)$ & \multirow{4}{*}{0.84} \\
\hline Sometimes & $18(36.7)$ & $2(22.2)$ & $23(26.7)$ & & $29(32.2$ & $16(32.0)$ & \\
\hline Never & $8(16.3)$ & $1(11.1)$ & $11(12.8)$ & & $13(14.5)$ & $6(12.0)$ & \\
\hline Non response & $4(8.2)$ & $3(33.3)$ & $12(14.0)$ & & 10 (11.1) & $4(8.0)$ & \\
\hline
\end{tabular}

ORS has saved the lives of millions of children, especially in developing countries. [11] In this study, a majority of the health workers utilized ORS in treating childhood diarrhoea suggesting that this is largely available. This finding corroborates the findings from other studies which had earlier noted that ORS is the main fluid used for pre-hospital treatment in children with diarrhoea. [7,12] The use of SSS, a solution that is easily prepared in the health facility and at home, was the second commonest choice of fluid for rehydration. The less frequent use of intravenous fluids indicates the less frequent indication for intravenous rehydration and possibly, the lack of expertise in its use. Another recommended management modality for childhood diarrhoea is zinc and this was utilized by the majority of the respondents. This observation represents an improvement on the $35 \%$ prescription rate reported by Omuemu et $a l .,{ }^{[6]}$ and this may be the effect of training activities over the years. 
Table Vb: Association between treatments used for management of childhood diarrhoea, the cadre of health care worker and training on diarrhoea

\begin{tabular}{|c|c|c|c|c|c|c|c|}
\hline \multirow{3}{*}{$\begin{array}{l}\text { Treatment modality and } \\
\text { frequency of use }\end{array}$} & \multicolumn{3}{|c|}{ Cadre of Health care worker } & \multirow[t]{3}{*}{$\boldsymbol{P}$} & \multicolumn{2}{|c|}{ Trained } & \multirow[t]{3}{*}{$\boldsymbol{P}$} \\
\hline & CHEW & $\mathrm{CHO}$ & Nurse & & Yes & No & \\
\hline & $\mathrm{n}(\%)$ & $\mathrm{n}(\%)$ & $\mathrm{n}(\%)$ & & $\mathrm{n}(\%)$ & $\mathrm{n}(\%)$ & \\
\hline \multicolumn{8}{|l|}{ "Diastop" } \\
\hline Always & $8(16.3)$ & 1 (11.1) & $9(10.5)$ & \multirow{4}{*}{0.83} & $9(10.0)$ & $7(14.0)$ & \multirow{4}{*}{0.81} \\
\hline Sometimes & $14(28.6)$ & $2(22.2)$ & $20(23.3)$ & & $23(25.6)$ & $12(24.0)$ & \\
\hline Never & $18(36.7)$ & $4(44.4)$ & $37(43.0)$ & & 39 (43.3) & $23(46.0)$ & \\
\hline No response & $9(18.4)$ & $2(22.2)$ & $20(23.3)$ & & $19(21.1)$ & $8(16.0)$ & \\
\hline \multicolumn{8}{|l|}{ "Diapec" } \\
\hline Always & $4(8.2)$ & $0(0.0)$ & $4(4.6)$ & \multirow{4}{*}{0.003} & $5(5.5)$ & $1(2.0)$ & \multirow{4}{*}{0.16} \\
\hline Sometimes & $8(16.3)$ & $6(66.7)$ & $9(10.5)$ & & $7(7.8)$ & $9(18.0)$ & \\
\hline Never & $21(42.9)$ & $0(0.0)$ & $41(47.7)$ & & 44 (48.9) & $24(48.0)$ & \\
\hline Non-response & $16(32.6)$ & $3(33.3)$ & $32(37.2)$ & & $34(37.8)$ & $16(32.0)$ & \\
\hline \multicolumn{8}{|l|}{ "Lomotil" } \\
\hline Always & $9(18.4)$ & $1(11.1)$ & $6(7.0)$ & \multirow{4}{*}{0.45} & $11(12.2)$ & $3(6.0)$ & \multirow{4}{*}{0.23} \\
\hline Sometimes & 15 (30.6) & $2(22.2)$ & $24(27.9)$ & & $21(23.4)$ & $18(36.0)$ & \\
\hline Never & $18(36.7)$ & $4(44.5)$ & $36(41.9)$ & & 38 (42.2) & $22(44.0)$ & \\
\hline Non-response & $7(14.3)$ & $2(22.2)$ & $20(23.2)$ & & $20(22.2)$ & $7(14.0)$ & \\
\hline \multicolumn{8}{|l|}{ Thalazole" } \\
\hline Always & $4(8.2)$ & $0(0.0)$ & $1(1.2)$ & \multirow{4}{*}{0.22} & $3(3.3)$ & $0(0.0)$ & \multirow{4}{*}{0.36} \\
\hline Sometimes & $10(20.4)$ & $2(22.2)$ & $23(26.7)$ & & $18(20.0)$ & $13(26.0)$ & \\
\hline Never & $20(40.8)$ & $5(55.6)$ & $38(44.2)$ & & $38(42.2)$ & $25(50.0)$ & \\
\hline Non-response & 15 (30.6) & $2(22.2)$ & $24(27.9)$ & & $31(34.5)$ & $12(24.0)$ & \\
\hline \multicolumn{8}{|l|}{ Zinc } \\
\hline Always & $42(85.7)$ & $7(77.8)$ & 75 (87.3) & \multirow{4}{*}{0.74} & $76(84.5)$ & $45(90.0)$ & \multirow{4}{*}{0.62} \\
\hline Sometimes & $3(6.1)$ & $1(11.1)$ & $3(3.5)$ & & $5(5.5)$ & $3(6.0)$ & \\
\hline Never & $0(0.0)$ & $0(0.0)$ & $1(1.2)$ & & $1(1.1)$ & $0(0.0)$ & \\
\hline Non-response & $4(8.2)$ & $1(11.1)$ & $6(7.0)$ & & $8(8.9)$ & $2(4.0)$ & \\
\hline
\end{tabular}

Table VI: knowledge of health care workers about prevention of diarrhoea

\begin{tabular}{|c|c|c|c|c|c|c|}
\hline \multirow[t]{3}{*}{ Prevention strategy } & \multicolumn{6}{|c|}{ The opinion of Health care workers } \\
\hline & \multicolumn{2}{|c|}{ Agree } & \multicolumn{2}{|c|}{ Disagree } & \multicolumn{2}{|c|}{ Undecided } \\
\hline & $\mathrm{n}$ & $\%$ & $\mathrm{n}$ & $\%$ & $\mathrm{n}$ & $\%$ \\
\hline Breastfeeding & 142 & 86.1 & 2 & 1.2 & 21 & 12.7 \\
\hline Hand Washing & 143 & 86.7 & 0 & 0 & 22 & 13.3 \\
\hline Proper sewage disposal & 137 & 83.0 & 0 & 0 & 27 & 16.4 \\
\hline Boiling of drinking water & 100 & 60.6 & 29 & 17.6 & 28 & 17.0 \\
\hline $\begin{array}{l}\text { Antibiotics during } \\
\text { diarrhoea }\end{array}$ & 80 & 48.5 & 43 & 26.1 & 42 & 25.4 \\
\hline Zinc during diarrhoea & 131 & 79.4 & 10 & 6.1 & 24 & 14.5 \\
\hline Immunization & 110 & 66.7 & 20 & 12.1 & 35 & 21.2 \\
\hline
\end{tabular}




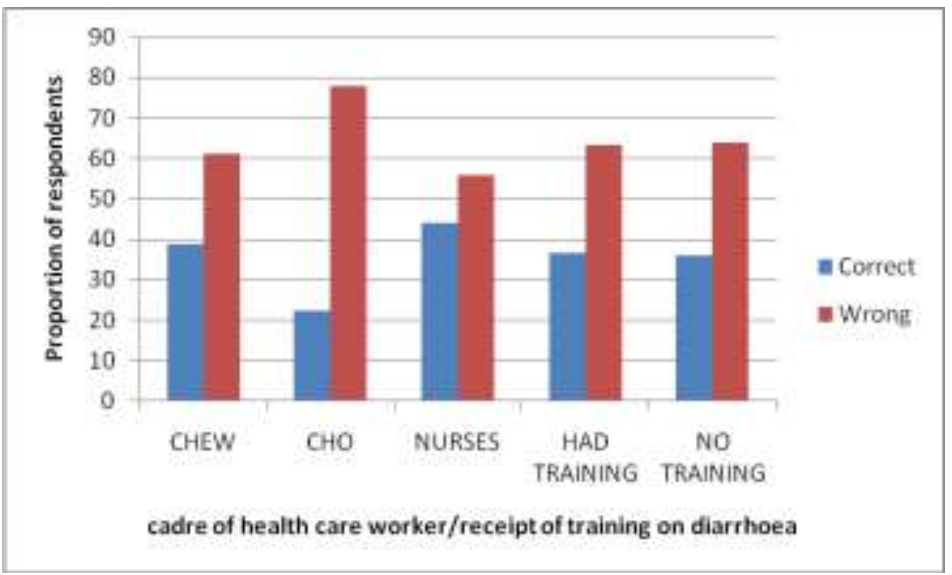

Figure 1: Association between the cadre of health care workers/ receipt of training on diarrhoea and knowledge of composite signs of dehydration

The preparation of ORS is an important determinant of the outcome of management in diarrhoea. Using hypertonic solutions may result in hypertonic dehydration, which is more difficult to treat. Caregivers have been reported to have offered incorrectly prepared SSS to their children with diarrhoea. [12] This is not surprising as the finding in this study suggests that a majority of the respondents do not know how to prepare SSS. Poor knowledge about the preparation of SSS by health care workers has previously been reported from Jigawa State in Nigeria where only $30.7 \%$ of the health workers studied could correctly prepare SSS. [5]

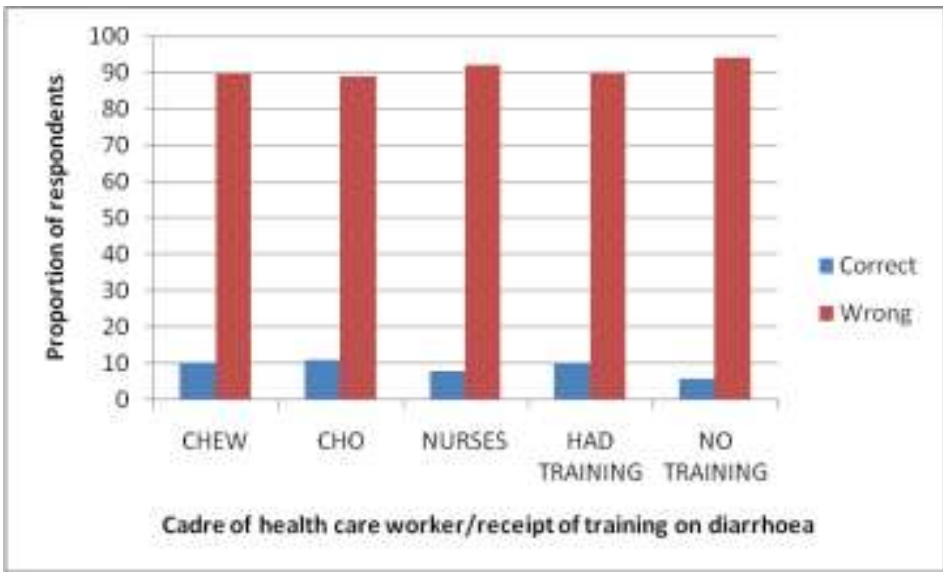

Figure 2: Association between the cadre of health care worker/receipt of training on diarrhoea and knowledge of preparation of Salt Sugar Solution

The poor knowledge about SSS may be a result of the reduced emphasis on the need for it since ORS is widely available. However, some studies have even reported incorrect preparation of ORS which is unexpected as these commercially prepared salts usually have directions for preparation on the packs. ${ }^{[12,13]}$
The poor knowledge about SSS preparation recorded in this study has far-reaching implications as health workers are usually the sources of health information for many caregivers. In a study from Benin City, up to $70 \%$ of caregivers whose children had diarrhoea got their information from health care workers. [8] Occasionally, health facilities may not have 
ORS in stock and health care workers may need to prepare SSS to rehydrate children with diarrhoea. Incorrectly prepared SSS may result in mismanagement and further electrolyte derangements with poor outcomes. Such low competence in the preparation of SSS by health care workers, as reported in this study and from Jigawa State, [5] should justify regular training/retraining of health care workers.

The frequency of the use of antibiotics in the management of diarrhoea in this study is rather high. This corroborates reports that the inappropriate use of antibiotics for diarrhoea and upper respiratory tract infections is common and such inappropriate use has been described as a major contributor to the current public health problem of increasing antibiotic resistance. [14,15] Metronidazole was the commonest antibiotic that respondents would use in the treatment of diarrhoea in this study. This is in keeping with the report by Abdu et al. [5] Other drugs that have been found to either be harmful or not useful in childhood diarrhoea were reported to be used by health care workers in this study. These practices need to be actively discouraged during the training of health care workers.

With regards to prevention, almost half of the respondents thought that antibiotic use during diarrhoeal episodes is a prevention strategy. This may explain the high proportions who would utilize different antibiotics in the treatment of childhood diarrhoea in this study. According to standard guidelines, antimicrobial therapy is not routinely recommended in childhood diarrhoea. [16] They are only recommended in specific instances such as bloody diarrhoea, cholera and when specific aetiologic agents are isolated from stool specimens. [16] Preventive strategies like hand washing, breastfeeding and the use of zinc were well known to the respondents. However, more than a third of the respondents did not know that boiling of drinking water and immunization are preventive strategies for diarrhoea. Boiling water is a means of providing clean drinking water, especially if the means are available. Health care workers are in a good position to advocate for the introduction of the Rotavirus vaccine and their knowledge that other vaccines in the routine schedule such as measles vaccine prevent diarrhoea helps them to make efforts to improve coverage of such vaccines.

The knowledge, attitude, and practice of health care workers concerning childhood diarrhoea have very important implications on the accuracy of information disseminated to caregivers, especially concerning the role of ORS and antibiotics in the management of childhood diarrhoea. While the respondents in the present study had good knowledge about the use of oral rehydration, the propensity to use antibiotics and the inability of the majority of them to correctly prepare SSS may portend negative outcomes for diarrhoeal morbidity and mortality in children.

There was no significant difference in most of the knowledge and practice items tested, based on cadre and based on prior training. This may be a reflection of the general level of practice. It may thus, require other innovative ways to improve the knowledge and practice of these health care workers. Nurses and CHEWs were more likely to know that irritability, small volume urine and loss of skin turgor are features of dehydration. Nurses and CHEWs were significantly more likely to use intravenous fluids than CHOs. Nurses and CHEWs may be more likely to be involved in patient care and work with doctors who utilize these practices, than the CHOs, hence their better knowledge in these areas.

\section{Conclusion}


This study has identified areas that would need strengthening in the training/educational programmes for health care workers. It is recommended that regular training and retraining should be conducted for health care workers, as was done for this group of health workers. The management of common childhood conditions should be included in the curriculum for such educational activities. Consistent supportive supervision with an emphasis on key areas in the evaluation and management of the child with diarrhoea may be required for sustained knowledge and improved level of practice.

Acknowledgements: We acknowledge with thanks, Miss Omozusi Sadoh for data entry into a computer.

Authors' Contributions: AES conceptualized the study, participated in data collection, analysed and interpreted the data, drafted the manuscript and approved the final draft. $\mathrm{CO}$ contributed to the concept, participated in data collection, reviewed the initial draft and approved the final draft. IM contributed to the concept, analysed and interpreted the data, reviewed the initial draft and approved the final draft

Conflict of interest: None declared

Funding: Self-funded

Publication History: Submitted 29 May 2019; Revised 03 September 2019; Accepted 11 September 2019.

\section{References}

1. Victoria CG, Bryce J, Fontaine O, Monasch R. Reducing deaths from diarrhoea through oral rehydration therapy. Bull World Health Organ 2000; 78: 1246-1255.

2. Global burden of diseases 2016 diarrhoeal disease collaborators. Estimates of the global, regional and national morbidity, mortality and aetiologies of diarrhoea in 195 countries: a systematic analysis for the global burden of disease study 2016. Lancet Infect Dis 2018; 18:1211-1228.

3. Global burden of diseases diarrhoeal disease collaborators. Estimates of global, regional and national morbidity, mortality and aetiologies of diarrhoea: a systematic analysis for the global burden of disease study 2016. Lancet Infect Dis 2017; 17: 908948.

4. World Health Organization, United Nations Children's Fund. Ending preventable child deaths from pneumonia and diarrhoea by 2025: The integrated global action plan for pneumonia and diarrhoea (GAPPD) World Health Organization 2013. Available at: https://apps.who.int/iris/bitstream/handle /10665/79200/9789241505239_eng.pdf;jsessi onid=64A1448D0A870E99E775A5CF83C40F0 6? sequence $=1$ Accessed on $11^{\text {th }}$ February 2019.

5. Abdu HA, Olosunde ZO, Zango AA. Owogbenja MD. Assessing the capacity of community health workers on the current management of childhood diarrhoea in Jigawa State, Nigeria. Jos J Med 2013; 7: 2731.

6. Omuemu VO, Ofuani JJ, Kubeyinje IC. Knowledge and use of Zinc supplementation in the management of childhood diarrhoea among healthcare workers in public primary health facilities in Benin City, Nigeria. Global J Health Sci 2012; 4: 68-76.

7. Uchendu UO, Emodi IJ, Ikefuna AN, Prehospital management of diarrhoea among caregivers presenting at a tertiary health institution: implications for practice and health education. Afr Health Sci 2011; 11: 41-47.

8. Iduoriyekemwen NJ, Osarogiagbon WO. Maternal knowledge of practices that cause diarrhoea and diarrhoeal disease prevention. Kanem J Med Sci 2011; 2: 50-56.

9. World Health Organization. Integrated Management of Childhood illness Chart Booklet. World Health Organization 2014. Available at:

https://apps.who.int/iris/bitstream/handle L10665/104772/9789241506823_Chartbook_ 
eng.pdf?sequence $=16$ Accessed on $25^{\mathrm{TH}}$ January 2019.

10. Udoh EE, Odey FA, Effa EE, Esu EB, Meremikwu MM. Facility-based evaluation of under-fives with diarrhoea in Cross River State, Nigeria: a clinical audit. Int J Contemp Pediatr 2016; 3: 1173-1177.

11. Tanmaya M, Patil VD, Rajshekar W, Hiremath MB. The role of antibiotics in childhood diarrhoea. Rec Res Sci Technol 2010; 2: 55-56.

12. Okoh BANM Alex-Hart BA. Home management of diarrhoea by caregivers presenting at the diarrhoea training unit of a tertiary hospital in southern Nigeria. Brit J Med Med Res 2014; 4(35): 5524-5540.

13. Anand R, Mandal A, Singh A. Oral rehydration solution in infantile diarrhoea: make sure it is given properly! J Fam Med Prim Care 2017; 6: 173-174.

14. Kotwani A, Joshi PC, Jhambi U, Holloway K. Prescriber and dispenser perceptions about antibiotic use in acute uncomplicated childhood diarrhoea and upper respiratory tract infections in New Delhi: Qualitative study. Indian J Pharmacol 2017; 49: 419-431.

15. Sadoh WE, Sadoh AE, Eki-Udoko FE. Parental contribution to over-prescription of antibiotics for sore throat. Niger J Paediatr 2015; 42: 98-102.

16. World Health Organization. The treatment of diarrhoea: a manual for physicians and other senior health workers. Chapter 2 Page 5. $4^{\text {th }}$ Rev. World Health Organization 2005. Available at: https//apps.who.int/iris/handle/10665/43 209. Accessed on 15th April 2019.

\begin{tabular}{|c|c|} 
This is an Open Access document licensed for distribution under the terms and conditions of the Creative \\
Commons Attribution License (http://creativecommons.org/licenses/by-nc/4.0). This permits unrestricted, \\
non-commercial use, reproduction and distribution in any medium provided the original source is adequately \\
cited and credited.
\end{tabular}

